Motrivivência $\quad$ v. 27, n. 46, p. 154-170, dezembro/2015

\title{
ESCOLA, EDUCAÇÃO FÍSICA E JUVENTUDE: caminhos para cidadania
}

Marcel Ivan Dos Santos?

\section{RESUMO}

O estudo investigou as contribuições da educação física e das manifestações do lazer imersas no âmbito cultural, na formação política e cidadã de jovens. Para tanto na parte inicial foi analisado todo o marco legal referente à disciplina educação física escolar, apontando o caminho percorrido por esta disciplina e sua culminância enquanto formadora de cidadãos, bem como foi identificado às aproximações desta com as práticas de lazer dos jovens. Constatou-se que a disciplina educação física na escola atualmente tem um papel relevante na contribuição para a cidadania, visto que a mesma possui instrumentos e conhecimentos diferenciados daqueles chamados tradicionais no mundo escolar que despertam um novo olhar dos jovens.

Palavras-chave: Juventude; Educação Física; Lazer; Escola; Cidadania

1 Mestre em Educação Física. Mestre em Cultura e Turismo. Professor da Prefeitura de Serra/Espírito Santo, Brasil. E-mail: marcelivan1@gmail.com 


\section{INTRODUÇÃO}

A percepção da presença do jovem nas sociedades latino-americanas, que se estruturou na década de 1950 e, de certa forma, vigorou até 1970, articula um conjunto de noções que vincula as ideias de modernização a projetos de mudança, apoiados sobre a figura do jovem estudante. Num plano, projetos pessoais e familiares de ascensão social pela escolarização (ABRAMO, 2007).

Com o desenvolvimento da sociedade industrial há um destaque para este grupo de idade correspondente a adolescência que ao criar a disjunção entre infância e a maturidade, tornou necessário um segundo processo de socialização que consiste na preparação dos jovens para assunção de vários papéis, tais como a profissão, ao casamento, e a cidadania política, que os coloca diante da necessidade de enfrentar uma série de escolhas e decisões que de certa forma impacta nas políticas públicas (ABRAMO, 2007).

As disciplinas que compõem o currículo do sistema de ensino são afetadas pelos conflitos advindos das questões referentes às políticas públicas e têm um papel fundamental quando se pensa a cidadania. No Brasil, a Educação Física Escolar configura-se enquanto componente curricular obrigatório da educação básica e detém um importante papel de formar cidadãos.

A discussão na Educação Física como promoção de cidadania foi intensificada a partir do Plano de Metas e Compromisso Todos pela educação, cuja função da Educação Física foi determinada nas seguintes diretrizes:
[...] VII - ampliar as possibilidades de permanência do educando sob responsabilidade da escola para além da jornada regular;[...] VIII - valorizar a formação ética, artística e a educação física; [...] XXIV - integrar os programas da área da educação com os de outras áreas como saúde, esporte, assistência social, cultura, dentre outras, com vista ao fortalecimento da identidade do educando com sua escola;[...] XXVI transformar a escola num espaço comunitário e manter ou recuperar aqueles espaços e equipamentos públicos da cidade que possam ser utilizados pela comunidade escolar; [...] XXVII - firmar parcerias externas à comunidade escolar, visando a melhoria da infraestrutura da escola ou a promoção de projetos socioculturais e ações educativas. ${ }^{2}$

É pertinente destacar que o conceito de cidadania nos remete a aquisição dos direitos civis, políticos e sociais destacado por Marshall em 1967, bem como os seus deveres. Marshall (1967, p.76) define direito social como "tudo que vai desde o direito a um mínimo de bem estar econômico e segurança ao direito de participar, por completo na herança social e levar a vida de um ser civilizado de acordo com os padrões que prevalecem na sociedade".

Na visão de Coutinho (2008, p. 5051), “cidadania é a capacidade conquistada por alguns indivíduos, ou (no caso de uma democracia efetiva) por todos os indivíduos, de se apropriarem dos bens socialmente criados, de atualizarem todas as potencialidades de realização humana abertas pela vida social em cada contexto historicamente determinado".

O conceito de cidadania plena ou ampliada é detalhado em Carvalho (2008), 
ao assegurar que trata de um termo complexo estabelecido historicamente, que combina a liberdade, a participação e a igualdade, além da garantia dos três tipos de direitos: civis, políticos e sociais. Este conceito assegura aos cidadãos o amparo legal de suas necessidades, desejos e aspirações, sendo construído por meio da identidade nacional e envolve uma série de especificidades, religião, língua, guerra, etc. O cidadão pleno seria aquele que fosse titular dos três direitos. Cidadãos incompletos seriam os que possuíssem apenas alguns dos direitos. Os que não se beneficiassem de nenhum dos direitos seriam não-cidadãos.

As instituições mais intimamente ligadas ao direito social são o sistema educacional e o próprio Estado. O Estado é peça fundamental na trama que compõe os direitos sociais e outras categorias interligadas a eles. Este se apóia em preceitos legais que anunciam a educação enquanto direito. ${ }^{3}$ As vias que o Estado utiliza para possibilitar o acesso aos diretos são as políticas públicas, estas são "consolidadas" a partir de leis e normatizações para a estruturação do sistema de ensino. Nesse sistema, as ações de governo se remetem à organização do sistema educacional através das secretarias, além da construção e manutenção de escolas.

Pensando nessa perspectiva, algumas ações do sistema educacional imprimem à disciplina escolar Educação Física um papel de promoção de cidadania.
As evidências dessa situação estão tanto na Lei de Diretrizes e Bases da Educação (LDB), nos Parâmetros Curriculares Nacionais (PCNs), quanto nas Orientações Curriculares Nacionais que são legalmente os regentes do sistema educacional brasileiro; mediante tais documentos, a Educação Física é um componente curricular obrigatório, tendo como um de seus objetivos, formar para a cidadania.

Assim, tomando como pressuposto que a escola é lugar onde o indivíduo começa a interagir com o outro e posteriormente com o mundo que o rodeia, a fim de constituir-se como um ser autônomo, emancipado - cidadão. Pensamos que a escola também é o instrumento para elaborar os intelectuais de diversos níveis, superando o modo de pensar precedente e o pensamento concreto existente, com vistas a transformar os processos ideológicos que os oprimem e impedem a emancipação (GRAMSCl, 1972).

Por outro lado, como aborda Sposito (1994) e Carrano (2011), atualmente o processo de socialização do jovem sob o ângulo da escola produz novo conjunto de relações marcadas pelo seu aspecto tenso e descontinuo. A primeira expressão dessa incongruência ocorre no desencontro entre as esperanças construídas pelas famílias em torno do valor da escola e as aspirações juvenis, produzidas em um ambiente não mais colorido pela crença nos benefícios imediatos na instrução para a ascensão

3 A Constituição Federal Brasileira de 1988 em seu artigo 205 contempla a educação como “direito de todos e dever do Estado e da família, será promovida e incentivada com a colaboração da sociedade, visando ao pleno desenvolvimento da pessoa, seu preparo para o exercício da cidadania e sua qualificação para o trabalho" (BRASIL 1988). Nesse documento que baliza os direitos e deveres tanto do Estado quanto da população brasileira, fica evidente que a educação deve promover tanto o desenvolvimento pessoal, quanto a preparação para o trabalho e a formação cidadã, possibilitando a todos o acesso à herança social, cultural e econômica da nação. 
social e melhoria das condições de vida, tão importantes para a geração anterior. Para o jovem, este desencontro entre a expectativa inicial, gestada na convivência familiar, e a experiência cotidiana, que nega essas aspirações, é demasiadamente evidente.

Assim, ao percebemos que a escola perde espaço nesse processo de socialização entre os jovens, é necessário um trabaIho mútuo de diversas disciplinas e propostas pedagógicas. Neste estudo, destacamos como a educação física e as manifestações do lazer podem contribuir nesse processo de socialização e formação humana para a cidadania haja visto que no plano legal esta também é competência desta disciplina.

Com base no exposto, considerando a importância da escola na formação humana, e o protagonismo dos jovens no mundo social, nos perguntamos se a educação física escolar e as manifestações do lazer podem contribuir na formação dos jovens cidadãos, sobretudo no que diz respeito preparação destes jovens para assunção dos papeis relativos à cidadania política?

O presente estudo tem abordagem qualitativa, realizado através da pesquisa documental e bibliográfica. Foram utilizados como fonte de dados, os documentos oficiais, Lei de Diretrizes e Bases da Educação (LDB), os Parâmetros Curriculares Nacionais (PCNs) que dizem respeito ao Ensino Fundamental, e as Orientações Curriculares Nacionais para Educação Física, que fazem referência ao Ensino Médio, sendo este último referência elementar para a análise das possibilidades da relação estudada no artigo. É relevante ressaltar que apesar desses documentos guardarem diferenças nas formas e nos conteúdos, ambos direcionam a disciplina de Educação Física na escola tendo como princípios a formação para cidadania. Também foram utilizados, teses e dissertações acerca da temática da juventude, cidadania e educação física, a fim de verificar as contribuições da educação física e das manifestações do lazer na formação política dos jovens cidadãos.

\section{Um pouco sobre a juventude}

A partir do século XIX, fim da Segunda Guerra Mundial, a concepção moderna de juventude é marcada por inúmeras transformações: o alongamento da transição entre a infância e a vida adulta, a escolaridade como etapa intrínseca a condição juvenil, o retardamento da entrada no mundo do trabalho e o aparecimento de formas de consumo e de produção cultural típicas desses segmentos.

A juventude constitui um referente conceitual que precisa de contextualização e especificidade desde suas acepções mais básicas: momento da vida, grupo social, estado de animo, estilo de vida, entre outras.

De acordo com Margulis e Urresti (1998, p. 1),

há distintas maneiras de ser jovem no marco da intensa heterogeneidade que se observa no plano econômico, social e cultural. Não existe uma única juventude: na cidade moderna as juventudes são múltiplas, variando em relação a características de classe, o lugar onde vivem e a geração a que pertencem e, além disso, a diversidade, o pluralismo, o estourar cultural dos últimos anos se manifestam privilegiadamente entre os jovens que oferecem um panorama sumamente variado e móvel que abarca seus comportamentos, referências identitárias, linguagens e formas de sociabilidade. 
Juventude é um significante complexo que contem em sua intimidade, múltiplas modalidades que levam a processar socialmente a condição de idade, tomando em conta a diferenciação social, a inserção na família e outras instituições, como por exemplo a escola, o gênero, o bairro, ou a microcultura grupal (MARGULIS; URRESTI, 1998).

O reconhecimento da heterogeneidade, a diversidade e a pluralidade, são eixos para um novo olhar das juventudes em nosso continente, e é baseado neste entendimento que operamos no artigo. "Ao mesmo tempo, os jovens são considerados portadores de valores ilustrados e como detentores dos instrumentos privilegiados para a transformação social: a política e a educação" (QUAPPER, 2001, p. 24).

O termo educação, no entanto, "recobre um campo extremamente vasto e importante que não se esgota na escola, pois os mecanismos por meio dos quais uma sociedade transmite a seus membros seus saberes, o saber-fazer e o saber-ser que ela estima como necessários a sua reprodução, são de uma infinita variedade" (DURU-BELLAT; VAN ZANTEN, 1992, p. 1), desse modo a escola deve acompanhar as mudanças da juventude. Tomamos como eixo desse novo olhar, a disciplina da educação física, bem como as manifestações de lazer.

\section{Educação Física: de manipulação à promo- ção de cidadania}

Atualmente a Educação Física se constitui enquanto componente curricular obrigatório para a educação básica. Mas a história nos mostra que nem sempre foi assim, e os caminhos percorridos pela Educação Física para despertar um debate sobre o reconhecimento de sua importância na escola foi árduo e marcado por interesses políticos. Ela é atravessada por todos esses movimentos, leis e diretrizes que caracterizam a educação brasileira e no seu início esteve incrustada de interesses de classes (FERSTENSEIFER, 1999, SOARES, 2004, SOARES et al, 1992).

Em meio às mudanças filosóficas da Educação Física, as políticas públicas educacionais também passaram a se reestruturar do decorrer dos anos 1990. Após um árduo processo de construção e intervenções políticas, a LDB é aprovada em 17 de dezembro de 1996 e sancionada três dias depois, 20 de dezembro. Ela trouxe em seu corpo, no referente à Educação Física a seguinte redação estampada em seu artigo 26 parágrafo $3^{\circ}$ : "A educação física, integrada à proposta pedagógica da escola, é componente curricular da Educação Básica, ajustando-se às faixas etárias e às condições da população escolar, sendo facultativa nos cursos noturnos" (BRASIL, 1996). Em $1^{\circ}$ de dezembro de 2003, devido às pressões sociais, a lei n. $10.793^{4}$ altera a citada redação, e a Educação Física passa a se tornar componente curricular obrigatório.

Sobre a relação entre a Educação Física e a cidadania, os PCNs defendem a utilização da concepção de cultura corporal de movimento acreditando que a mesma amplia a contribuição da Educação Física escolar para o pleno exercício da cidadania, "na medida em que, tomando seus con-

4 Disponível em < http://www010.dataprev.gov.br/sislex/paginas/42/2003/10793.htm > . Acesso em 27/04/2014. 
teúdos e as capacidades que se propõe a desenvolver como produtos socioculturais, afirma como direito de todos, o acesso e a participação no processo de aprendizagem" (BRASIL, 1998, p.30).

Os PCNs de Educação Física vislumbram:

Uma proposta que procura democratizar, humanizar e diversificar a prática pedagógica da área, buscando ampliar, de uma visão apenas biológica, para um trabalho que incorpore as dimensões afetivas, cognitivas e socioculturais dos alunos. [...] Os PCNs de Educação Física tratam das contribuições para a formação da cidadania sugerindo possíveis interfaces com os temas transversais, discutindo a natureza e a especificidade do processo de ensino e aprendizagem e expondo os objetivos gerais para o ensino fundamental (BRASIL, 1998, p. 15).

Os PCNs indicam ser objetivos do ensino fundamental a compreensão da cidadania como "participação social e política, assim como exercício de direitos e deveres políticos, civis e sociais, adotando, no dia-a-dia, atitudes de solidariedade, cooperação e repúdio às injustiças, respeitando o outro e exigindo para si o mesmo respeito" (BRASIL, 1998. p.10).

Visualizando de maneira ampliada o processo histórico que influenciou a Educação Física a se configurar enquanto componente curricular, podemos pontuar o pensamento de João Batista Freire:

Nos períodos da vida política brasileira mais fortemente dominados pelo autoritarismo, a Educação Física esteve mais amparada legalmente que em períodos mais democráticos. Apesar de tanto amparo, até hoje a Educação Física não conseguiu firmar-se no quadro mais geral da Educação Brasileira como uma atividade imprescindível à formação dos cidadãos. [...] a Educação Física brasileira, filha natural do militarismo e filha adotiva da medicina higiênica, não consegue livrar-se dessa paternidade. Hoje, passadas as ditaduras e diminuídas as influências dos militares, quem cuidará da Educação Física? Talvez, daqui para a frente ela só sobreviva se fizer necessária (FREIRE, 1997, p. 209).

Dessa forma, se por um lado a Educação Física se estabeleceu calcada no higienismo, no autoritarismo, no eugenismo e no esporte de rendimento, por outro lado, a mesma tem atualmente um papel relevante na contribuição para a cidadania.

Ainda no contexto dos ordenamentos legais, não podemos deixar de tratar das especificidades do ensino médio definidas nas Diretrizes Curriculares Nacionais (Resolução CEB no 3, de 26 de junho de 1998) que estão presentes nas Orientações Curriculares para o Ensino Médio - Conhecimentos de Educação Física (BRASIL, 2006). Esse documento aponta os seguintes princípios:

Art. $2^{\circ}$. A organização curricular de cada escola será orientada pelos valores apresentados na Lei 9.394, a saber:

I - os fundamentais ao interesse social, aos direitos e deveres dos cidadãos, de respeito ao bem comum e à ordem democrática;

II - os que fortaleçam os vínculos de família, os laços de solidariedade humana e de tolerância recíproca (BRASIL, 2006, p. 215).

Bem como em seu Artigo $3^{\circ}$, ressaltando que o currículo e as situações de ensino e aprendizagem deverão ser coerentes com princípios estéticos, políticos e éticos, abrangendo estes em seu tópico II. 
II - a Política da Igualdade, tendo como ponto de partida o reconhecimento dos direitos humanos e dos deveres e direitos da cidadania, visando à constituição de identidades que busquem e pratiquem a igualdade no acesso aos bens sociais e culturais, o respeito ao bem comum, o protagonismo e a responsabilidade no âmbito público e privado, o combate a todas as formas discriminatórias e o respeito aos princípios do Estado de Direito na forma do sistema federativo e do regime democrático e republicano (BRASIL, 2006, p. 216).

Assim, percebe-se que a disciplina da Educação Física no contexto escolar, possui uma particularidade em relação aos demais componentes curriculares e disciplinas, por tratar-se de um componente que contribui para a formação do cidadão com instrumentos e conhecimentos diferenciados daqueles chamados tradicionais no mundo escolar (BRASIL, 2006).

Apesar disso, Faria, Machado e Bracht (2012, p. 126) dizem que a Educação Física (EF) na escola é tida como uma disciplina de "segunda classe". Eles dizem que a visão que se tem: "[...] é da EF como auxiliar das outras disciplinas, uma espécie de apêndice da escola". Além disso, aparece como sendo um espaço de distração para os alunos, no qual eles se aliviam da tensão proporcionada pelo "esforço intelectual" despendido durante os momentos de sala de aula.

Observa-se, ao mesmo tempo, que estes momentos de "distração" podem oportunizar a aproximação com a realidade cotidiana dos jovens, de entender que esses se preocupam cada vez mais com o presente vivido, que a cada dia mais questionam regras, que idolatram e imitam ídolos esportivos, que vivem um contexto onde as drogas (inclusive as anabólicas) estão acessíveis. Jovens que se preocupam com o corpo e a moda como nunca antes, e que tem a necessidade do novo, da mudança e do diferente.

\begin{abstract}
Diante dessa pluralidade de usos da educação física na escola, cabe aqui uma tomada de posição acerca da sua contribuição na formação dos alunos. Essa tomada de decisão, que não se dá pela via do consenso, é fruto de toda uma série de debates que o campo da educação física vem realizando desde o final da década de 1980 (BRASIL, 2006, p. 218).
\end{abstract}

Como se percebe, os professores de Educação Física são chamados a tomar posicionamento político e pedagógico de sua prática educativa ainda que a partir de um debate não consensual dos ordenamentos legais (BRASIL, 2006). Dessa forma, as Orientações Curriculares Nacionais, apontam que a Educação Física no currículo escolar do ensino médio deve garantir aos alunos:
participação efetiva no mundo do traba- Iho no que se refere à compreensão do papel do corpo no mundo da produção, no que tange ao controle sobre o pró- prio esforço e do direito ao repouso e ao lazer; intervenção política sobre as iniciativas públicas de esporte, lazer e organização da comunidade nas mani- festações, vivência e na produção de cultura [...] (BRASIL, 2006, p. 225).

As práticas corporais dos sujeitos alicerçadas na educação física passam a ser mais uma linguagem na leitura do real, com outros métodos e técnicas. Por meio do movimento expressado pelas práticas corporais, os jovens retratam o mundo em 
que vivem: seus valores culturais, sentimentos, preconceitos, dentre outros aspectos (BRASIL, 2006).

Uma das grandes dificuldades apontadas pelas Orientações Curriculares Nacionais, encontradas na relação escolajuventude é a tendência que a instituição escolar tem de controlar e conceituar as culturas juvenis. Em diversas escolas, não se desenvolvem processos formativos que reconheçam essas culturas e ampliem as capacidades e os saberes que os jovens já possuem. A padronização das condutas, das formas de vestir, que muitas vezes não são discutidas com os alunos, colaboram com a destituição do protagonismo juvenil (BRASIL, 2006).

Relevante também frisar que os espaços de cultura e lazer, e as suas potencialidades, se colocam na perspectiva do direito. Falar em direito cultural implica criar condições de produção cultural. Assim, esperamos que uma política pública intersetorial seja capaz de promover a cidadania cultural, a qual é compreendida com uma quarta dimensão da cidadania além da civil, da social e da política - e se apresenta, como síntese das possibilidades, que a juventude têm, de vivenciar o espaço público (Cruz, 2003), para que amplie a capacidade crítica dos jovens frente à forte tendência da indústria cultural e do entretenimento de homogeneizar e reforçar guetos de identidade e práticas de consumo.

\section{O lazer e a cultura como meio e forma de educação e formação política}

A relação entre escola e a sociabilidade da juventude, já abordado por Brenner et al. (2008), Carrano (2011) e Dayrrel (2007a), e a suposta antipatia jovem para a política, no que diz respeito ao seu modo tradicional de participação (votação, partidos políticos), tem levado a vários grupos de jovens a recriar formas de estar presente nas questões que interessam e são significativos a eles (GAICOVIC, 2000).

$\mathrm{Na}$ verdade, não é que os jovens sejam apáticos à política, para além do voto, os jovens também contemplam outras formas de exercício da política, como a participação em mobilizações de rua, atuação em associações ou coletivos, e em conselhos e conferências ressalta a Pesquisa Agenda Juventude Brasil: Pesquisa Nacional Sobre Perfil e Opinião dos Jovens Brasileiros 2013 (BRASIL, 2013).

Sem negar a gravidade e complexidade em torno desta problemática apresentada acima, percebe-se que, "como esses jovens estão cada vez mais cedo expostos às contradições da sociedade, acabam também por gerar em seu cotidiano uma cultura específica e algumas formas de resistência, mesmo que de maneira diferenciada das que usualmente, enquanto "intelectuais", costumamos conceber e esperar" (MELO, 2003, p. 95). Devemos perceber que desse mesmo processo, surgem formas de resistência nem sempre vinculadas ao sentido clássico da política e esse é um processo complexo e às vezes confuso.

Dessa forma, é que devemos verificar como podemos trabalhar com base nas próprias especificidades das linguagens em uso e/ou geradas pelos jovens através da Educação Física e das manifestações de lazer - clips, internet, publicidade, são alguns exemplos mencionados por Melo (2003).

Outro autor que tece comentários interessantes a respeito de práticas educacionais inovadoras é Dayrell (2007b), que 
evidencia a cultura e a produção coletiva do conhecimento como forma de participação. Ele exemplifica outras atividades, como o incentivo a festivais culturais e esportivos, envolvendo os alunos e a comunidade, constituindo momentos de ampliação de sociabilidades. Projetos que possibilitem aos jovens a frequência em cinemas, teatros, museus, parques públicos e áreas de reserva, garantindo desse modo acesso aos bens culturais historicamente produzidos em articulação ao currículo escolar.

Apesar desses aspectos positivos, Dayrell (2007b) destaca que pode existir uma tendência a reduzir essas manifestações culturais a determinado tempo e espaço, no recreio, em atividades extraescolares, sem planejamento e nem avaliações, fazendo deles um meio de ocupar o tempo dos alunos, sem nenhum impacto no currículo. Além disso, alerta para a escolarização das expressões culturais que pouco tem a contribuir para a formação política e cidadã dos jovens.

Parece contraditório, mas conforme nos diz Tomassi (2007, p.17)

Uma forma de resistência é também contornar os cercos da segregação na "comunidade" e no local, circular pela cidade e mais além, circular entre diferentes espaços e múltiplas identidades, não "vestir a camiseta" mas assumir, para cada espaço e circunstância, diferentes identidades. Assim, um jovem rappeiro é, ao mesmo tempo, militante do movimento negro, cantor de gospel, trabalhador de ONG, multiplicador de economia solidária e consumidor dos últimos objetos eletrônicos e dos vestuários à moda. Outro jovem trabalha como assessor de uma deputada para pagar os seus estudos de marketing e publicidade, mas ao mesmo tempo milita numa rede juvenil regional, investe na criação de uma produtora independente de vídeos, faz estágio numa TV e defende a causa ambientalista. E, assim, se constroem percursos de socialização plurais, que permitem fugir dos rótulos, das caixinhas identitárias, do controle dos programas, das estatísticas e das classificações, da vida reduzida aos mínimos vitais, para construir formas de vida e produzir sentido.

Autores como Fischer apud Hennigen (2010) tem a compreensão de que tais representações promovem modos de ser jovem alinhados aos atuais interesses do capitalismo, e da relativização da importância da mídia face ao acesso e as diferentes posições sociais. De fato, existe uma exposição maior e uma possível delimitação imposta pelos meios de comunicação que influenciam as culturas juvenis, formando certos modos de ser. Porém, isso não se configura como verdade absoluta.

“Os jovens lançam mão da dimensão simbólica e expressiva como a principal e mais visível forma de comunicação, expressa no comportamento e nas atitudes com os quais se posicionam diante de si mesmos e da sociedade" nos informa Dayrell (2007, p. 53). Esta assertiva vai ao encontro com o que expõe Morin (2008), quando diz que o fenômeno comunicacional é complexo, não se esgota na presunção da eficácia do emissor e a influência da mídia depende de diversos fatores, como usos, contextos, filtros, percursos individuais, entre outros que podem e devem ser pedagogicamente contextualizados no ambiente escolar.

É imperativo ressaltar que tais manifestações culturais não são tomadas como únicas e nem se constituem como esteriotipos em relação aos modos de ser jovem. 
O conceito de cultura relaciona-se à forma como o humano legitima suas práticas historicamente, cuja construção se estabelece a partir dos esforços do grupo social para construir uma consciência de classe, que de fato é uma consciência política. Para Gramsci (2004), a questão da cultura se enraíza na história e não pode ser tratada abstratamente, sob pena de cair no vazio, pois para ele a cultura não constituiu um simples jogo de ideias que se resolve fora da realidade.

Em outras palavras, as manifestações culturais exploradas no contexto da Educação Física, e do lazer, e os exemplos mencionados aqui, bem como suas diversas expressões podem funcionar como articuladoras de identidades culturais e referência na elaboração de projetos de vida individuais e coletivos, uma forma de participação social, cidadã e porque não política?

O conceito clássico de política é tratado em Bobbio (2002), e indica tudo o que se refere à cidade e, consequentemente, o que é urbano, civil, público, e até mesmo sociável e social. No que diz respeito à participação do cidadão na política, Teixeira (1997, p. 194) nos diz que este conceito envolve dois aspectos contraditórios.

a) o "fazer ou tomar parte", por indivíduos, grupos, organizações que expressam interesses, identidades, valores, que poderiam situar-se no campo do particular mas significam espaço para heterogeneidade, diversidade, pluralidade; b) o elemento cidadania, no sentido cívico cujas dimensões de universalidade, generalidade, igualdade de direitos, responsabilidade e deveres se procura enfatizar (TEIXEIRA, 1997, p. 194).

Nesta perspectiva, quando falamos de formação política e cidadã, o fazemos de forma crítica, evitando os riscos dos culturalismos e a desconsideração para com a questão econômica e com a luta de classes em consonância com o debate proposto por Melo (2003). Ou seja, é pensar em novas formas de atuação e intervenção para além das formas tradicionais usualmente observadas em nossas práticas cotidianas e principalmente nas escolas.

E isso não significa utilizar a "cultura" como chamariz da "política", mas considerar que na "cultura" em si, existem formas de conscientização e resistência que se diferenciam do sentido clássico da "política". No caso dos jovens, devido a atual configuração da sociedade, tal perspectiva de atuação para ser alvissareira (MELO, 2003, p. 96).

Pensando assim, colocamos em primeiro plano à reflexão acerca da possibilidade do jovem ser caracterizado como sujeito da ação política, já que a juventude é uma experiência marcada pela tensão entre público e privado, e que muitas vezes o reconhecimento da voz, da ação e da experiência juvenil se dá através de uma mediação, seja ela adulta ou institucional conforme aborda Mayorga (2013).

Esta reflexão exige a superação da perspectiva dicotomizada (sociedade $x$ indivíduo), que potencializa nosso olhar “para à dinâmica e ao processo da relação entre juventude e política com foco nas interações, e não nas partes" (MAYORGA, 2013, p. 345). Uma vez que não se pode compreender a sociedade em partes, ou como uma somatória de perspectivas, ações e posições individuais, nem deixar de atribuir aos indivíduos seu papel nas formações sócio-históricas. Em suma, não podemos partir de uma análise restrita da 
influência do contexto da vida dos jovens, ou mesmo sem a participação deles no centro das práticas e dos debates.

Dessa maneira, é que podemos enxergar novas formas de agir também dentro do contexto escolar, chamar o jovem a participar por meio de outras linguagens, que não são únicas, e também não se reduzem no contexto de participação política, parece ser uma forma adequada e criativa de quebrarmos paradigmas em nossos contextos de atuação na escola e na sociedade.

Ao compreendermos a importância das manifestações do lazer no contexto das culturas juvenis, ressaltamos, portanto, que o lazer é uma atividade social condicionada historicamente pelas condições de vida material e pelo capital cultural, que constitui sujeitos e coletividades. É importante dizer que tempo livre não implica necessariamente lazer. O tempo livre do trabalho, pode significar o espaço da opressão e da falta de oportunidades. Esse é o caso do desemprego e da desocupação, situação vivida por uma expressiva parcela de jovens brasileiros, que deve ser problematizada nessas aulas (BRENNER et al, 2008, CARRANO, 2011).

$\mathrm{O}$ erro de se compreender a juventude como uma realidade homogênea aparece com frequência no senso comum em relação ao tempo livre e ao lazer. Tal fato ocorre, talvez, pela percepção de que o tempo da juventude, e o tempo das culturas juvenis, seriam somente os momentos de fruição de divertimentos, prazeres e distância relativa do mundo do trabalho, que a nosso ver não corresponde com a realidade, já que partimos da premissa que o lazer "se constitui como um fenômeno tipicamente moderno, resultante das tensões entre capital e trabalho, que se materializa como um tempo e espaço de vivências lúdicas, lugar de organização da cultura, perpassado por relações de hegemonia" (MASCARENHAS, 2003, p. 17).

Complementando o conceito proposto por Mascarenhas, corroboramos com Padilha (2006) quando nos diz que o lazer deve constituir um espaço de organização da cultura, ampliando as oportunidades para se questionar os valores da ordem social vigente, de maneira que as pessoas não apenas vivenciem, mas também produzam cultura. Pelo exposto, a cultura institui uma expressiva possibilidade para se conceber o lazer em nossa realidade histórico-social.

É a partir deste entendimento e realidade, que identificamos na Educação Física, sobretudo através das manifestações culturais do lazer, uma possibilidade de aproximação com as atividades desses jovens. Mas, na medida em que inferimos a respeito do diálogo entre Educação Física, escola e lazer, faz-se necessário outros esclarecimentos que não se esgotam aqui nesse texto.

O primeiro, referente à escola como espaço principal de fazer amigos (Brenner et al, 2008) cujos dados foram obtidos pela pesquisa Perfil da juventude brasileira, o que aponta a relevância do pedaço como locus de sociabilidade. E segundo, que a Educação Física, deve se preocupar com questões que dizem respeito ao lazer que atravessem os discursos e práticas dentro da sistematização de seus conteúdos, que não reproduzam uma ideia do lazer como atividades facilitadoras na aprendizagem, e que não restrinjam sua atuação apenas ligada aos conteúdos físicos e esportivos. Mas, que avancem sua discussão para problematizar e possibilitar a ampliação na formação cultural dos alunos, o que implica 
tratar também outros interesses culturais do lazer, como por exemplo, os interesses artísticos, manuais e turísticos (SILVA, 2011).

Acrescentamos ainda que o professor deve partir de uma perspectiva que valorize a cultura corporal, em que o movimento é uma construção cultural, constituído de dimensões históricas, políticas e sociais. A Educação Física deve pensar na tarefa de educar para o lazer, em diálogo com o entendimento do movimento como forma de comunicação com o mundo, que é constituído de cultura e ao mesmo tempo possibilitado por ela (BRACHT, 1997).

Quando falamos em possibilidade de intervenção através do lazer, não podemos deixar de mencionar acerca do seu duplo aspecto educativo. Trata-se de um posicionamento baseado em duas constatações: a primeira, que o lazer é um veículo privilegiado de educação; a segunda, que para a prática das atividades de lazer, é necessário o aprendizado, o estímulo, a iniciação, que possibilitem a passagem de níveis menos elaborados, para níveis mais elaborados, complexos, com o enriquecimento do espírito crítico, na prática ou na observação. Verifica-se, assim, um duplo aspecto no processo educativo - o lazer como veículo e como objeto de educação, ou seja, educação pelo lazer e educação para o lazer (MARCELLINO, 2006).

Outrossim, de acordo com as Orientações Curriculares Nacionais,

é de grande relevância, a compreensão de que os alunos que participam e realizam as aulas de educação física no ensino médio são sujeitos socioculturais. $\mathrm{O}$ que significa que devemos superar uma certa visão estereotipada da noção de alunos, buscando dar Ihes outro significado. O desafio é buscar entender esses alunos na sua condição de jovens, compreendendo-os nas suas diferenças, percebendo-os como sujeitos que se constituem como tal a partir de uma trajetória histórica, por vezes com visões de mundo, valores, sentimentos, emoções, comportamentos, projetos de mundo bastante peculiares (BRASIL, 2006, p. 220).

Para além disso, o mesmo documento ainda nos alerta que devemos desmitificar as ideias sobre os jovens que os associam à noção de crise de identidade, irresponsabilidade, ou até problema social. Em oposição a esses entendimentos, partimos da premissa de que os jovens são, hoje, cidadãos e sujeitos de direitos e não apenas projetos para o futuro, ou adultos em potencial.

Dessa forma, pensar sobre as relações entre o lazer, a Educação Física, a juventude e a cidadania ainda constitui um grande desafio para as escolas. É evidente que deve haver o diálogo da escola com as culturas juvenis. Para tanto, é importante assumir a escola como um espaço público e cultural significativo que perceba que seus alunos também pertencem a outros espaços de criação cultural. As manifestações de rua, as festas, as práticas de esporte, constituem lugares de formação e produção de cultura pelos jovens, que precisam ser reconhecidos e trabalhados dentro da escola.

A leitura da realidade pelas práticas corporais permite fazer com que estas se tornem uma nova forma de enxergar o mundo, nos faz pensar que existe uma variedade de formas de apreender e intervir na realidade social que deve ser valorizada na escola numa perspectiva mais ampliada de formação (BRASIL, 2006).

Essa articulação de temas e conteúdos, dos quais incluímos o lazer, envolvidos 
pelo tratamento pedagógico, dará condições ao professor de fazer a Educação Física cumprir algumas de suas perspectivas em relação à formação de seus alunos, o acúmulo e a produção cultural a partir dos conhecimentos construídos e a capacidade de intervenção político e social acerca das definições públicas na organização e gestão política do espaço, dos equipamentos e dos serviços públicos para as práticas corporais da comunidade, e a formação para a cidadania.

\section{CONSIDERAÇÕES FINAIS}

Entendemos que o percurso histórico que a educação física fez para se firmar enquanto disciplina importante no currículo escolar não foi uma tarefa fácil, ao analisarmos os aparatos legais e ao observamos a prática docente, percebemos que a temática da formação cidadã permeia e incide o campo da educação física, bem como das manifestações de lazer que são um meio de socialização e um espaço frequentemente utilizado pelos jovens.

Tratar a educação física enquanto uma importante possibilidade de permitir que a educação pública se desvencilhe das enlaças que a estagnaram numa função de manutenção do poder vigente, de interesses políticos e de formar apenas para o trabalho, parece ser o papel da educação física quando pensada como componente curricular de uma educação compreendida como direito social, viabilizadora da promoção da cidadania.

Está claro que nós não temos receitas, mas o contexto educacional em geral, bem com a educação física aponta para a necessidade de urgente ressignificação, pois, assim como não existem receitas para os males que atingem a escola e a formação dos jovens, inexiste um diagnóstico de que a mudança não acontecerá. O que nos parece ser possível é que a educação e a sociedade de uma maneira geral possam assumir uma postura desconstrutora, mas, também transformadora da escola, e para que isto aconteça vão depender dos sujeitos (agentes), de políticas educacionais, de governos, de projetos e ações que visem mudanças (ZIENTARSKI et al, 2009).

Nesse sentido, como já salientado, o que nos parece mais próximo é trabalhar com base nas próprias especificidades das linguagens geradas pelos jovens. Na escola, apontamos a educação física e as manifestações de lazer como potenciais meios de educação, não só a educação formal, mas a educação política, e a formação humana e cidadã.

A importância dada à cidadania nos documentos que norteiam a educação e a educação física é o que nos estimula a pensar e investigar sobre qual tem sido o papel da educação física nessa relação. As respostas possíveis para tantos questionamentos serão buscadas a partir de um futuro aprofundamento da temática através de uma pesquisa de campo.

\section{REFERÊNCIAS}

ABRAMO, H. W. Considerações sobre a tematização social da juventude no Brasil. Juventude e Contemporaneidade. - Brasília: UNESCO, MEC, ANPED, 2007.

ALMEIDA JR., A. S.; MORAES, A. C. ; OLIVEIRA, C. M. ; SANTOS, K. C.; BRASILEIRO, L. T. ; OLIVEIRA, N. R. C. 
. Conhecimentos de Educação Física. In: BRASIL, Secretaria de Educação Básica/ MEC (Org.). Orientações Curriculares para o Ensino Médio. Brasília: Ministério da Educação, Secretaria de Educação Básica, 2006, p. 213-239.

BETTI, M. Violência em Campo: dinheiro, mídia e transgressão às regras do futebol espetáculo. Ijuí: Ed. UNIJUÍ, 1997.

BOBBIO, N. et al. Dicionário de Política. 12. ed. Brasília: UnB, 2002.

BRASIL. Pesquisa Agenda Juventude Brasil: Pesquisa Nacional Sobre Perfil e Opinião dos Jovens Brasileiros 2013, Observatório Participativo da Juventude, Brasília, 2013.

BRASIL. Lei de Diretrizes e Bases da Educação Nacional. 1996.

BRASIL. Parâmetros curriculares nacionais:

Educação Física. 1998. Secretaria de

Educação Fundamental. - Brasília: MEC /SEF.

BRASIL. Parâmetros curriculares nacionais:

Educação Física. 2001. Ministério da Educação. Secretaria da Educação Fundamental. - 3. ed. - Brasília: A Secretaria.

BRASIL. Orientações Curriculares para

o Ensino Médio. Brasília: Ministério da Educação, Secretaria de Educação Básica, 2006, p. 213-239.

BRASIL. Constituição [da] República

Federativa do Brasil. Brasília: Senado Federal, 1988.

BRACHT, V. As ciências do esporte no Brasil: uma avaliação crítica. In: FEREIRA NETO, A. GOELLNER, S. \& BRACHT, V. V (orgs.). As Ciências do Esporte no Brasil. Campinas: Autores Associados, 1995.

Conhecimento e Especificidade. In:
SOUZA, E. S. e VAGO, T. M. (Org.). Trilhas e Partilhas: Belo Horizonte: Ed. Do autor, 1997.

BRENNER, A. K.; DAYRRELL, J.; CARRANO, P. Capítulo 2: Modo de vida e transição para a vida adulta. Juventude brasileira: culturas do lazer e do tempo livre. Brasil. Ministério da Saúde. Fundação Oswaldo Cruz. Um olhar sobre o jovem no Brasil / Ministério da Saúde, Fundação Oswaldo Cruz. - Brasília: Editora do Ministério da Saúde, 2008.(Série B. Textos Básicos de Saúde)

CARVALHO, J. M. Cidadania no Brasil: o longo caminho. 10 ed. Rio de Janeiro: Civilização Brasileira, 2008.

CARRANO, P. Jovens, escolas e cidades: Desafios à autonomia e à convivência. Revista Teias v. 12, n. 26, set./dez. 2011, p. 07-22.

COUTINHO, C. N. Contra a corrente: ensaios sobre democracia e socialismo. São Paulo: Cortez, 2008.

CRUZ, R. R. Ciudadanias culturales. Revista Ultima Década, Viña Del Mar, n. 17, 2003.

DAYRELL, J. A escola faz as juventudes? reflexões em torno da socialização juvenil. Educ. Soc., Campinas, v. 28, n. 100. (Especial), out. 2007a, p. 11051128.

DAYRELL, J. Escola e práticas educativas: quando os jovens são atores. In. CARRANO, P. Debate - Juventudes em rede: jovens produzindo educação, trabalho e cultura, 2007b.

DURU-BELLAT, VAN ZANTEN, A. Sociologie de I'école. ie de I'école Paris: Armand Colin, 1992.

FARIA, B. A; MACHADO, T. S; BRACHT, V. A inovação e o desinvestimento pedagógico na Educação Física 
escolar: uma leitura a partir da teoria do reconhecimento social. Motriz, Rio Claro, v.18, n.1, jan-março, 2012, p.120-129.

FENSTERSEIFER, P. E. A educação física na crise da modernidade. Tese de Doutorado, UNICAMP, Campinas - São Paulo, 1999.

FREIRE, J. B. Aspectos da Legislação brasileira sobre educação física. In:

Educação de corpo inteiro: teoria e prática da educação física. São Paulo: Scipione, 1997.

GIDDENS, A. A Iongevidade da adolescência. Folha de São Paulo, São Paulo, caderno Mais, 2 jan. 2000, p. 30-31.

GOICOVIC, I. Del control social a la política social. La conflictiva relación entre los jóvenes populares y el Estado en la historia de Chile. Última Década. $\mathrm{n}^{\circ} 12$. Valparaíso: Edicionescidpa, 2000.

GRAMSCI, A. Os intelectuais e a organização da cultura. Tradução de Carlos Nelson Coutinho. $4^{\mathrm{a}}$ Ed. Rio de Janeiro: Civilização Brasileira, 1972.

GRASMCI, A. Escritos Políticos. Organização e tradução Carlos Nelson Coutinho, co-edição, Luiz Sergio Henrique e Marco Aurélio Nogueira. 3a ed., v.1. Rio de janeiro: Civilização Brasileira, 2004.

HENNIGEN, I. A gente se vê por aqui? A recepção da novela Malhação pelos jovens. Pesquisas e Práticas Psicossociais 5(2), São João del-Rei, agosto/dezembro, 2010.

MASCARENHAS, F. Lazer como prática de Liberdade. Goiânia-GO, UFG, 2003 MARGULIS, M.; URRESTI, M. La construcción social de la condición de juventud. In. MARGULIS, M. et al.
Viviendo a toda: Jóvenes, territories culturales y nuevas sensibilidades. Editor María Cristina Laverde, Bogotá, D.C. Siglo del Hombre Editores. Departamento de Investigaciones Universidad Central, 1998.

MARSHALL, T. H. A Cidadania e Classe Social. In:. Cidadania, Classe Social e Status. Rio de Janeiro: Zahar Editores, 1967, p. 57-107.

MARCELLINO, N. C. Estudos do Lazer: uma introdução. 11 ed. Campinas: Autores Associados, 2006.

MAYORGA, C. Pesquisar a juventude e sua relação com a política - Notas Metodológicas. Estudos de Psicologia, 18(2), abril-junho/2013, p. 343-350.

MEDINA, J. P. S. A Educação Física cuida do Corpo e "Mente". Campinas: Papirus, 1986.

MELO, V. A. Lazer e juventude: o lazer como cultura e a cultura como forma de mobilização. In. MELO, V. A. Lazer e Minorias Sociais. São Paulo: IBRASA, 2003.

MORIN, E. A comunicação pelo meio. In. F. Martins \& J. M. Silva (Orgs.), A genealogia do virtual. Porto Alegre: Sulina, 2008, p. 11-19.

PADILHA, V. (Org.). Dialética do Lazer. 1. ed. São Paulo: Cortez, 2006

QUAPPER, K. D. Juventud o juventudes? Acerca de como mirar y remirar a lãs juventudes de nuestro continente. In: BURAK, Solum. Adolescencia y Juventud em América Latina, 2001.

SOARES, C. L. Educação Física: raízes européias e Brasil. 3.ed. Campinas: Autores Associados, 2004.

SOARES, C. L. et al. Metodologia do ensino de Educação Física. Coletivo de autores. São Paulo: Cortez, 1992. 
SOUZA JÚNIOR, M. O saber e o fazer pedagógicos da Educação Física na Cultura Escolar: o que é um componente curricular. In: CAPARRÓZ, F. E. (org.). Educação Física Escolar: Política, Investigação e Intervenção. Vitória: Proteoria. Vol.1. 2001. p. 81-92.

SILVA, T. F. Lazer, escola e educação física escolar: encontros e desencontros. Licere, Belo Horizonte, v.14, n.1, mar/2011.

SPOSITO, M. P. A sociabilidade juvenil e a rua: novos conflitos e ações coletivas na cidade. Revista Tempo Social. São Paulo: USP 5 (1-2), 1994.

TEIXEIRA, E. C. As dimensões da participação cidadã. Cadernos do CRH (UFBA), v. $26 / 27,1997$, p. 179-209.
TOMASSI, L. Espaços e tempos de participação: jovens brasileiros, espaços e tempos de participação política. In. CARRANO, P (org.). Debate juventudes em rede: jovens produzindo educação, trabalho e cultura, BOLETIM 24, 2007.

ZIENTARSKI, C; MORAES, A. P. C. C.; OLIVEIRA, O. S.; PEREIRA, S. M; SAGRILLO, D. R. A educação, a escola e seu papel na manutenção ou transformação social. In: VIII Seminário nacional de estudos e pesquisas "Historia, sociedade e educação no Brasil", 2009, Campinas. História, educação e transformação: tendências e perspectivas, 2009.

\title{
SCHOOL, PHYSICAL EDUCATION AND YOUTH: paths to citizenship
}

\begin{abstract}
The study investigated the contributions of physical education, and leisure practices immersed in the cultural, political and civic education of youth. In the initial part was analyzed throughout the legal framework relating to physical education discipline, pointing the path of this discipline and its relations to training of citizens, as well as identified approaches with the leisure practices of young people. It was found that the discipline of school physical education currently has a role in contributing to citizenship, since it has tools and knowledge differentiated from traditional school, what awaken a new opinion of youth.
\end{abstract}

Keywords: Youth; Physical Education; Leisure; School; Citizenship 
ESCUELA, LA EDUCACIÓN FÍSICA Y LA JUVENTUD: caminos a la ciudadanía

\section{RESUMEN}

El estudio investigó la contribución de la educación física y las prácticas de ocio inmersos en la formación cultural, política y cívica de la juventud. En la parte inicial se analizó todo el marco jurídico relativo a la disciplina de la educación física, señalando el camino de esta disciplina y sus relaciones con la formación de los ciudadanos, así como los enfoques identificados con las prácticas de ocio de los jóvenes. Se encontró que la disciplina de la educación física escolar en la actualidad tiene un papel en la contribución a la ciudadanía, ya que cuenta con las herramientas y conocimientos diferenciados de la escuela tradicional, lo que despiertan un nuevo dictamen de la juventud.

Palabras clave: Juventud; Educación Física; Ocio; Escuela; Ciudadanía

Recebido em: novembro/2014 Aprovado em: agosto/2015 